\title{
Concentrating solar power in sustainable tourism
}

\author{
M. Georgei ${ }^{1}$, J. Krueger ${ }^{1} \&$ B. Henning ${ }^{2}$

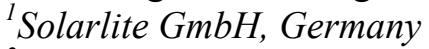 \\ ${ }^{2}$ Department of Housing Design and Rural Buildings, \\ Faculty of Agricultural and Environmental Sciences, \\ University of Rostock, Germany
}

\begin{abstract}
The world is becoming more aware everyday that not only resources are finite but also that the capability of natural systems to absorb societies' wastes and emissions may be even a more stringent limit. Meanwhile, many countries are attracting everyday more tourists, requiring more tourism developments which, in turn, increase the demand on those finite resources as well as the resulting emissions and wastes. It is essential for such countries to make wise technology choices. The objective of this paper is to explore the solar resort concept examining the use of solar energy and the possible application of concentrated solar power, CSP, systems in resorts located in the sun-belt region. A case study on the Maldives islands is taken as an example to demonstrate the technical and economical feasibility of CSP technology for a sustainable touristic island solution. This paper is the result of a study carried out by a team from different organizations and led by the author as the project manager of this project.
\end{abstract}

Keywords: sustainable tourism, island solutions, solar energy, $\mathrm{CO}_{2}$ emissions, solar share, CSP technology, co-generation, renewable energy, environment.

\section{Introduction}

Many new tourism developments are taking place on the Maldives inflicting a larger burden on the existing energy plants. Currently, electrical energy is mainly supplied through fuel operated generators located on the many islands forming the different Maldives Atolls. Due to the tropical hot humid weather conditions, one of the main high consumers is air-conditioning. This study was carried out to 
demonstrate the ability for the Maldives to reduce their dependency on diesel fuel as well as reduce its $\mathrm{CO}_{2}$ emissions. This would also meet the Maldivian's Government policy of becoming $\mathrm{CO}_{2}$ neutral within the next decade [1]. Several hotel and resort chains have also expressed their intention to decarbonise their resorts on the Maldives. Accordingly, there is a need to investigate different renewable energy applications in resorts. Parabolic trough technology being the more mature and successful technology among the CSP technologies has been chosen for this power plant project. Solarlite ${ }^{\circledR}$ parabolic troughs are used throughout the study for the simulation of the CSP technology. The case study demonstrated in this paper involves an existing resort on one of those islands.

\section{Working concept of CSP}

Figure 1 demonstrates the CSP concept. The sun radiations falling on the parabolic troughs are reflected by its mirrored surface and focused on one single focal line. A receiver pipe conveying water is installed along this focal line, which is heated up as a result of the concentrated reflected sun radiation to the extent that the conveyed water is instantly transformed into steam. This steam can be fed into a turbine where electricity is produced. The efficiency of such CSP plants is very high since the waste steam can be recycled and used in secondary purposes in addition to the main power output, known as cogeneration systems. For example, the waste heat available after electricity production from the turbine can be used for heating, cooling and air conditioning purposes.

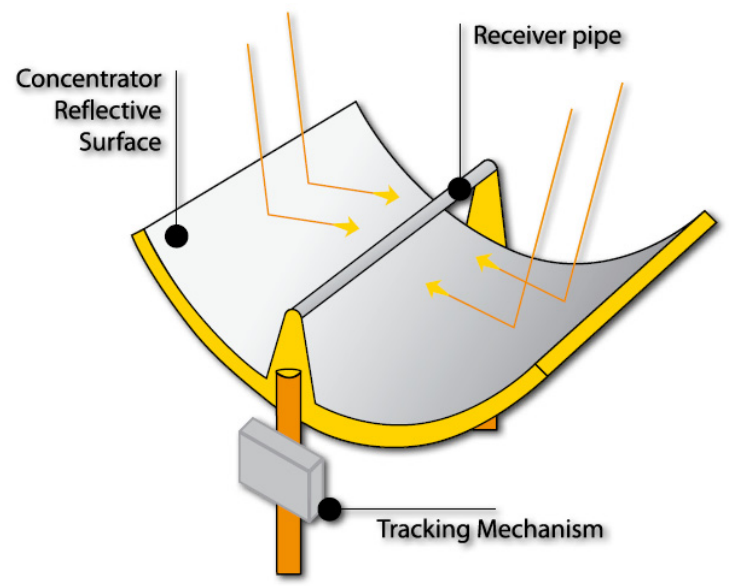

Figure 1: CSP concept. 


\section{Project concept}

\subsection{Objective}

The objective of this project is to build a CSP power plant with an electric output of $0.55 \mathrm{MW}_{\mathrm{e}}$ for an existing resort on one of the Maldivian islands. The usable waste heat after electricity productions is to be used for air conditioning, AC, and domestic hot water, DHW. The aim is to partly replace the usage of fossil fuels.

\subsection{Location and background}

The proposed project takes place on one of the islands in Baa Atoll located at ca. $100 \mathrm{~km}$ from Male. This is a 5 star luxurious hideaway resort which occupies a whole island and consists of 65 luxury villas. The energy demands are currently supplied by 4 diesel generators. The cooling and the heating demand of the resort are currently provided through electrically operated equipment such as electrical air-conditioning units and electrical hot water heaters. The total annual electricity consumption of the resort is ca. $4,483,108 \mathrm{kWh}_{\mathrm{e}}$ with a peak demand between $600-800 \mathrm{~kW}$.

\subsection{Data gathering and site assessment}

A site assessment was carried in order to choose the optimal location. Different sources of meteorological data and irradiation data in addition to environmental impacts, land availability, surrounding high obstacles and shading were all taken into consideration.

Though most of the Asian countries are located in the sun-belt region, not all of them have sufficient direct solar resources to employ CSP technologies. The Maldives enjoy better radiation conditions compared to many Asian countries in the sun-belt region. The assessment of the site indicated a good level of irradiation with an average annual direct normal irradiation, DNI, value of $1,791 \mathrm{kWh} / \mathrm{m}^{2}$ which is very suitable for CSP technology

\subsection{Co-generation design concept}

It is planned that the electrical consumption of the resort will be $350 \mathrm{~kW}_{\mathrm{e}}$ which is lower than the actual consumption after introducing the following measures:

- Use of more efficient equipment.

- Applying energy management systems.

- Improving the thermal insulation of buildings.

- Providing solar cooling through absorption chillers thermally operated.

- Use of cooling storage to extend the provision of AC after sunshine hours.

- Providing DHW using thermal energy.

- Use of hot water storage to extend the provision of DHW after sunshine hours.

The CSP plant is designed to produce net $500 \mathrm{~kW}_{\mathrm{e}}$ of electricity enough to cover the resort's own demand of $350 \mathrm{~kW}_{\mathrm{e}}$ peak during sunshine hours and the 
remaining produced power of $150 \mathrm{kWe}$ will be sold to the neighbouring island. The waste heat resulting from the turbine and amounting to $2,706 \mathrm{~kW}_{\text {th }}$ will be used by the resort for AC and DHW. Figure 2 is a schematic diagram showing the CSP cogeneration concept.

A site of $20,000 \mathrm{~m}^{2}$ is required for installing ca. $7,949 \mathrm{~m}^{2}$ of Solarlite 4600 collectors with rows oriented towards north south direction.

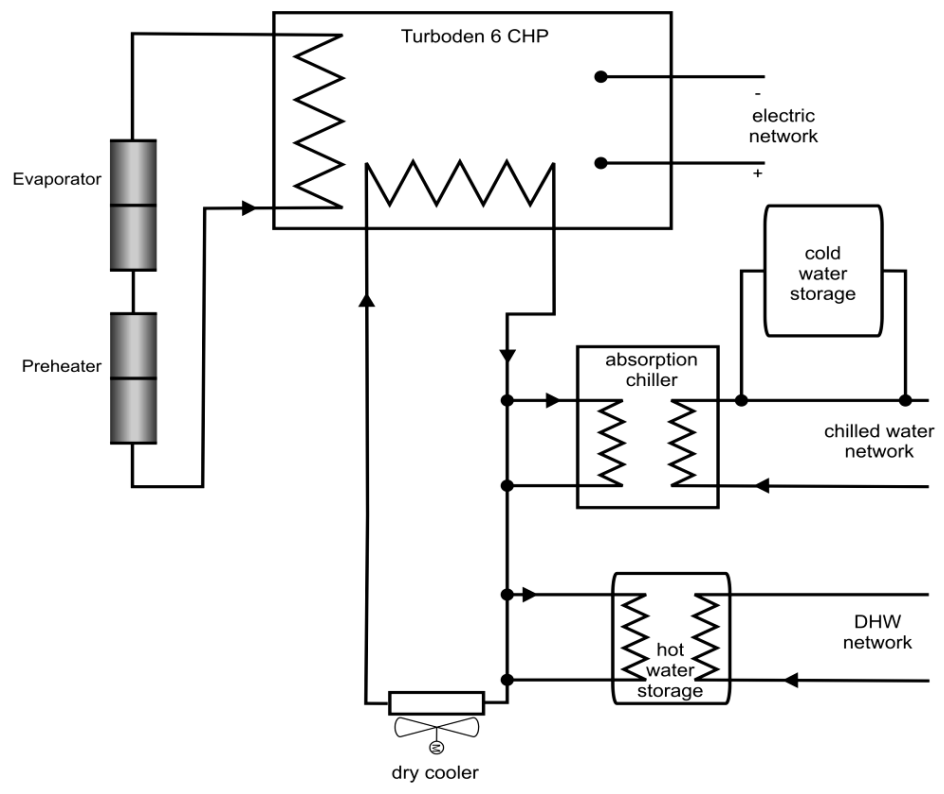

Figure 2: $\quad$ Schematic diagram for the CSP power plant concept.

\subsection{Current energy demand structure before the CSP plant}

Figure 3 shows the monthly repartition of the mean daily electricity consumption in $\mathrm{kWh} /$ day during the year 2006 which represents a typical year. It was noted that change in weather conditions on the Maldives do not have a strong effect on the electricity consumption. Figure 3 shows that the difference between the lowest daily consumption in September and the highest daily consumption in April is only $17 \%$ indicating that there is no real off-season.

Figure 4 shows the average hourly electricity consumption profile of a typical day in September 2006. Obviously most electricity is consumed between 1 and 9 p.m. This peak is most likely caused by the elevated air conditioning load due to higher outer temperatures. The remaining electricity is used to heat DHW, sea water desalination, laundry and kitchen equipment and lighting, and so forth. The peak electricity demand of this average day amounts to more than $600 \mathrm{~kW}$. 


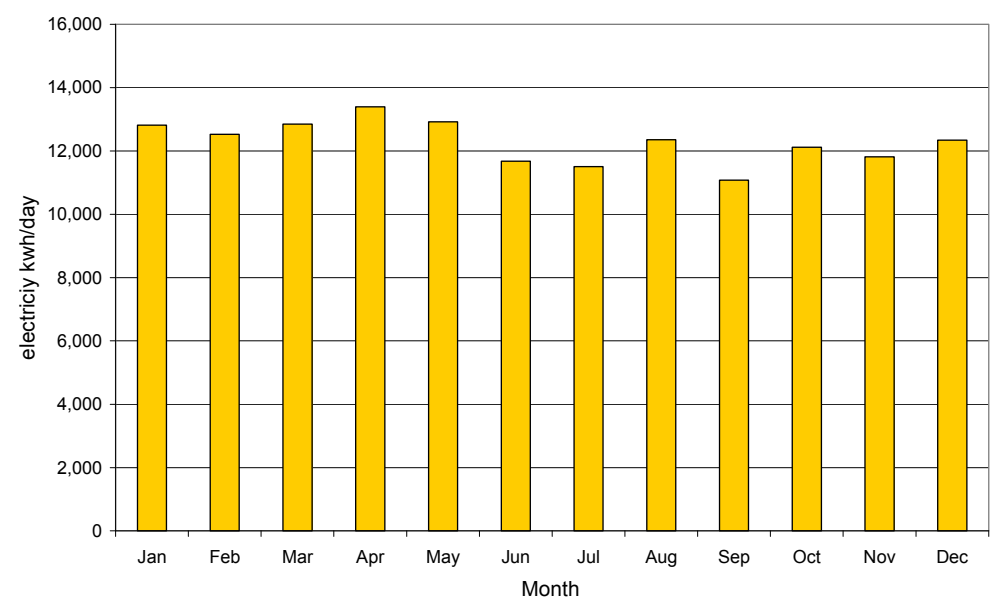

Figure 3: $\quad$ Average daily electricity consumption during the year 2006.

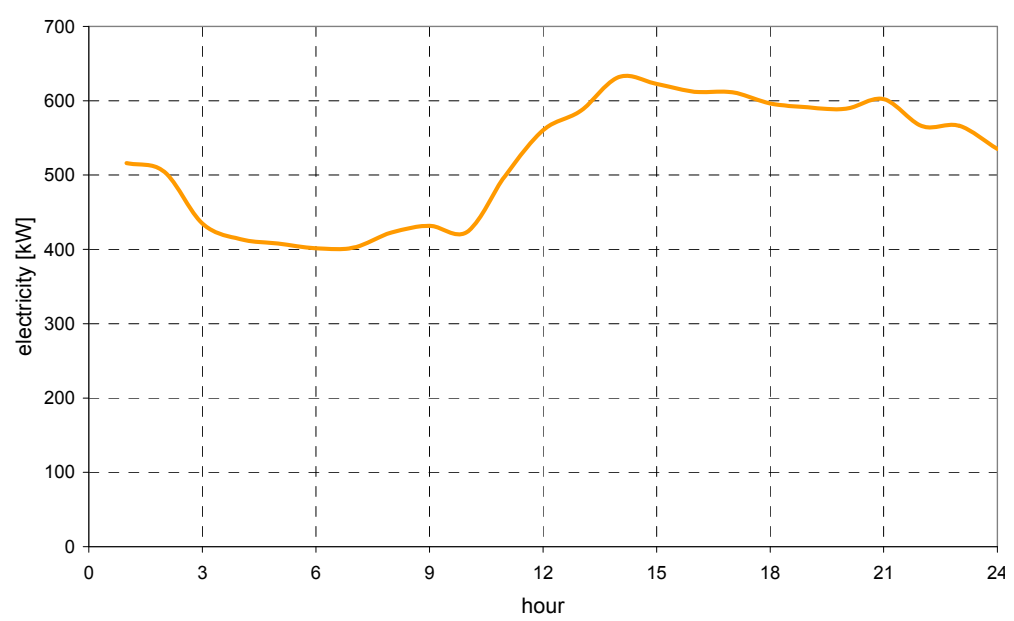

Figure 4: Mean hourly electricity consumption in September 2006.

The total annual consumption is $4,483,108 \mathrm{kWh}_{\mathrm{e}}$, equivalent to a fuel consumption of ca. 1,259,128 litres. In order to calculate the energy savings with the proposed solar system, the energy consumption of the existing cooling and heating installation was examined and used to determine the future load profile in case of using the CSP system. The daily repartition of the energy demand has been categorised as follows: $15 \% \mathrm{DHW}, 40 \% \mathrm{AC}$ and $45 \%$ other electrical consumers.

The graph in figure 5 shows the extrapolated demand structure of energy indicating the hourly demand of energy required for DHW, AC and other electrical consumers. 


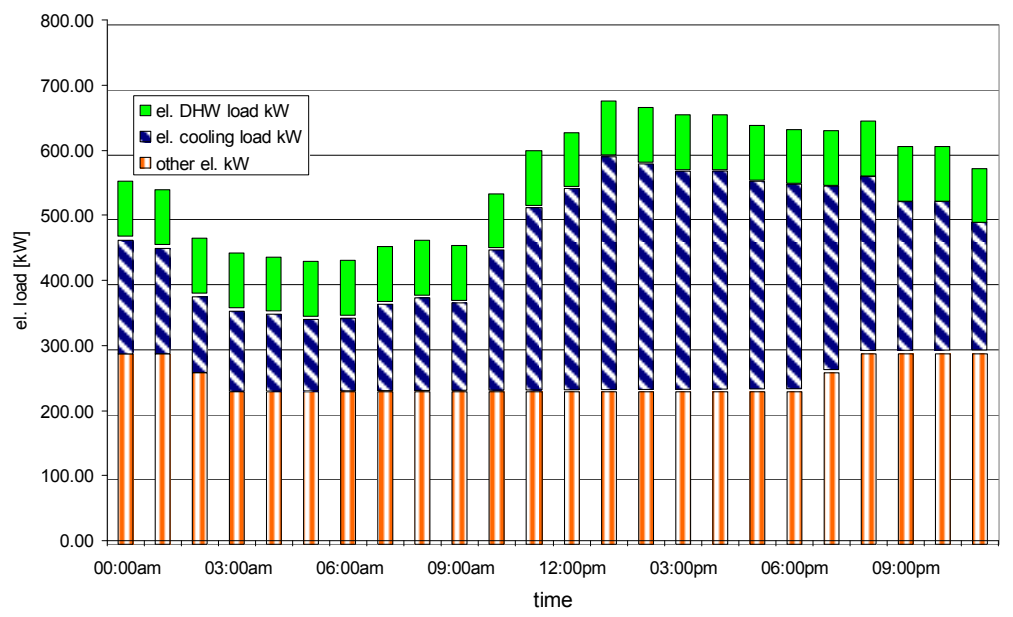

Figure 5: Hourly electricity consumption of different categories.

It is assumed that a hot water storage would be used to cover peak hot water demands. The electricity consumed for $\mathrm{AC}$ is at its maximum level during the afternoon while very low during the night. Other electric appliances are assumed to have a constant consumption during the day whereas only during the evening the consumption increases due to lighting.

\subsection{Energy demands after the CSP}

The daily AC load of all hotel rooms and villas is calculated to be $13,397 \mathrm{kWh}_{\mathrm{th}}$. On the other hand, the thermal DHW load of 2,233 kWh per day is calculated taking into account two peak-hour periods occurring in the morning between 4 and 10 a.m. and in the evening between 4 and 22 p.m.

Figure 5 has been used to define the energy loads to be used in designing the CSP capacity meeting the resort's requirements. The electrical load was adapted by shifting the consumption of some applications from night to day time when adequate solar energy is available. For example, laundry operation is usually carried out during night hours to overcome the peak hours during the day; however, in case of using CSP the AC and DHW will be provided using the thermal energy of the CSP plant. Hence, more electric power will be available during the day which allows the operation of the laundry equipment during sunshine hours. Figure 6 depicts the derived energy loads after adaptation to the CSP concept. 


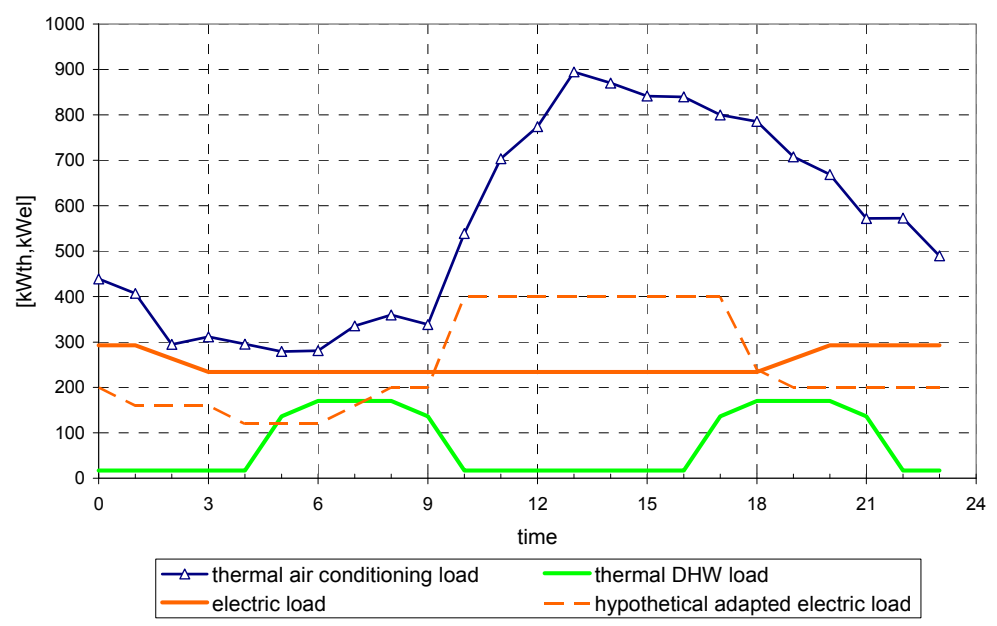

Figure 6: Derived thermal and electric daily load profile.

\subsection{Daily and annual energy yield}

Considering the weather data, energy load profiles and other technical parameters, the boundary conditions are defined and an annual energy yield calculation is carried out. The previous extrapolated energy loads, figure 6, are demonstrated below in figure 7 illustrating the hourly energy available from the sun versus the resort's demands. The graph also demonstrates the different levels of energy conversion from the moment of the sun radiation falling on the solar field until the end consumer. Dotted lines show energy demands. The blue, orange and green full line show the part of the energy covered by solar.

The annual energy yield by the CSP station is shown in the Sankey diagram in figure 8 . Theoretically, 7,852 MWh of thermal energy are deliverable by the solar field, of which only $6,984 \mathrm{MWh}$ are produced and transferred to the power block. The turbine will produce 1,056 MWh of electricity, of which $665 \mathrm{MWh}$ are to be consumed in the resort and the remaining $392 \mathrm{MWh}$ are to be sold to the neighbouring island. The heat rejected by the turbine amounts to 5,593 MWh, whereas only 3,534 MWh is used for the DHW- and AC systems. This means that more than 2,000 MWh of thermal energy is still available for other applications. If other thermal applications were available, this remaining waste heat can still be used and/or sold increasing the profitability of the CSP installation.

\subsection{Solar share}

The solar fraction indicates how much of the resort's energy requirements can be covered by solar energy replacing the existing fuel consumption by diesel 


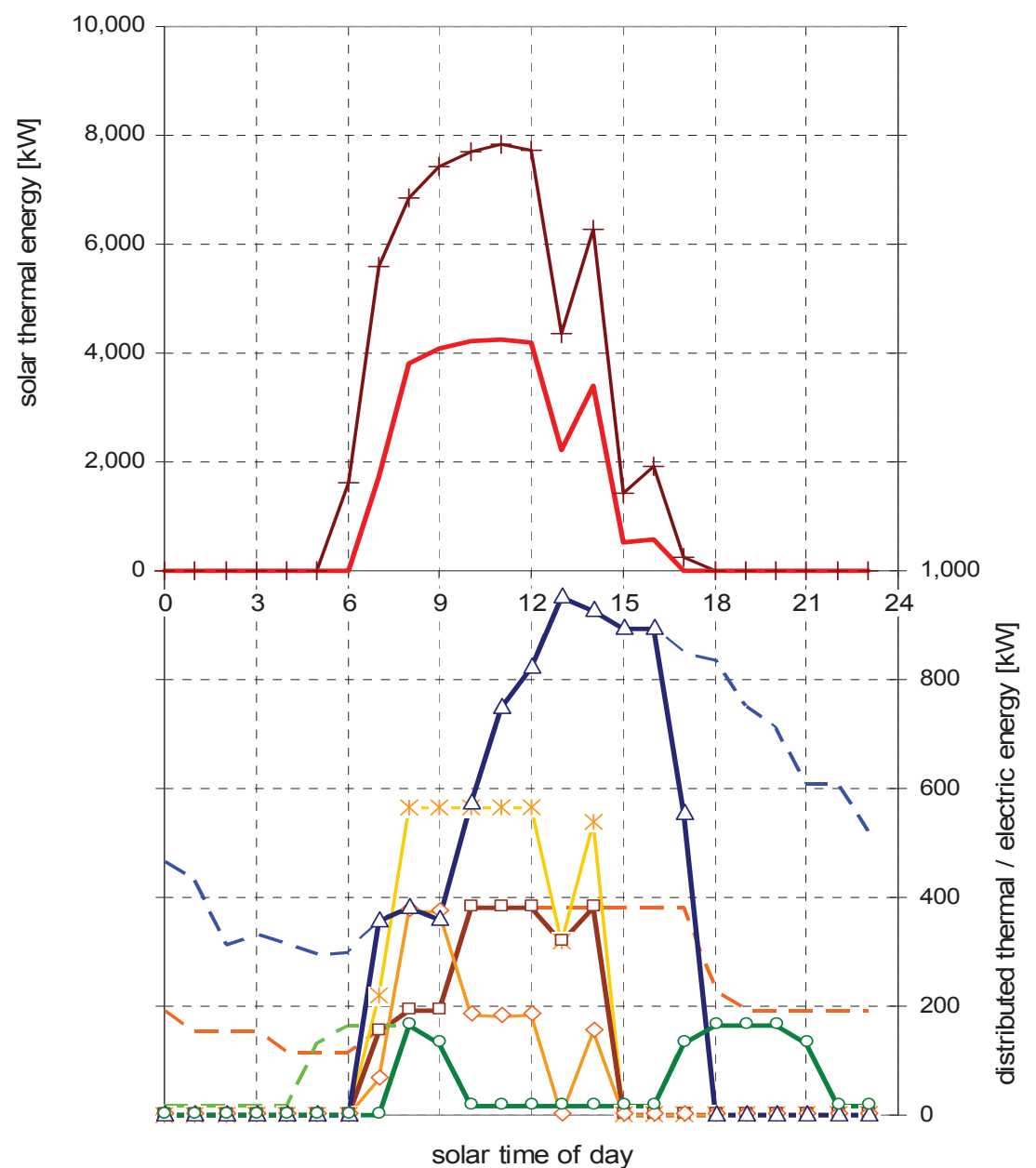

\begin{tabular}{|c|c|}
\hline $\begin{array}{l}-\_ \text {incident power to the field } \\
-\ldots \text { demanded el. power in the hotel resort } \\
-\square-\text { net power used for hotel consumption } \\
-\quad \text { demanded a.c. power in the hotel resort } \\
-\quad \text { DHW demand }\end{array}$ & $\begin{array}{l}- \text { thermal power of solar field } \\
-*-\text { net el. power generation } \\
- \text { a.c. power provided by chiller and CWS } \\
- \text { DHW demands covered }\end{array}$ \\
\hline
\end{tabular}

Figure 7: Energy produced during a representative day.

generators. Table 1 summarises the annual resort energy demand versus the demand fraction covered by CSP station. The solar fraction for electricity and AC amounts to $33 \%$ and $44.1 \%$ respectively while the solar fraction for DHW attains $85.2 \%$. The overall solar fraction for the resort is accordingly calculated 
to be $44.7 \%$. The solar fraction can be further increased if a storage system for steam is to be installed allowing the production of power during the nonsunshine hours. However, in this case study such steam storage was not considered sine the technology is still underdevelopment and, hence, due the initial cost are extremely high and not yet commercialised. Taking into account the above values, the diesel consumption in the existing status is compared to that after applying the CSP concept as in table 2. An annual amount of 1500 ton of $\mathrm{CO}_{2}$ emissions would be avoided.

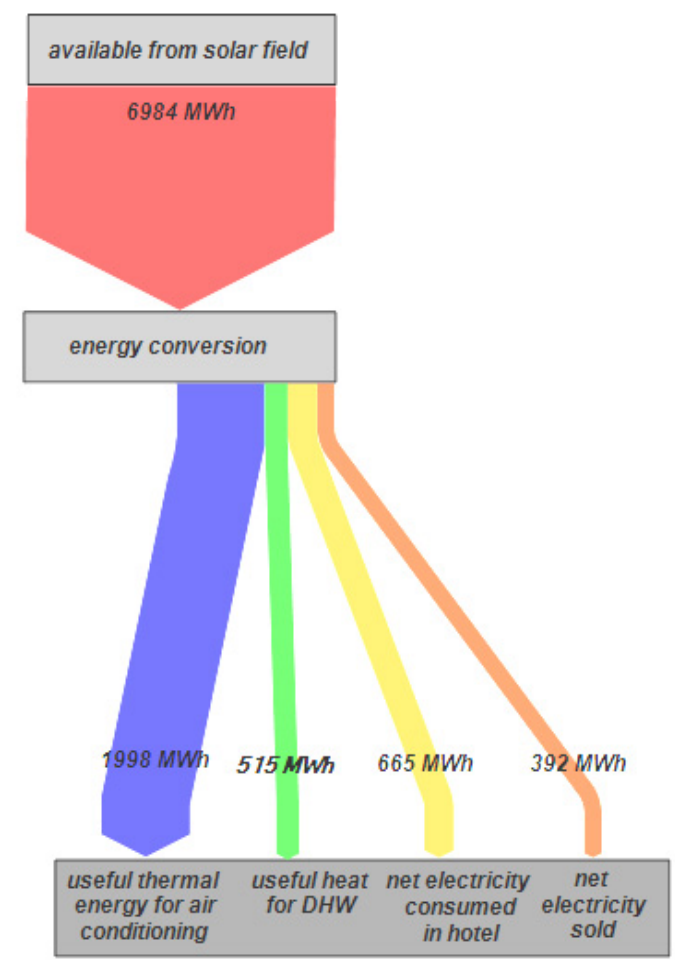

Figure 8: Sankey diagram of the annual energy yields.

Table 1: $\quad$ Solar fraction using CSP.

\begin{tabular}{|c|c|c|c|c|}
\hline & & & \multirow[b]{3}{*}{$\begin{array}{c}\text { Cooling } \\
\text { energy } \\
\left(\mathrm{MWh}_{\text {cooling }}\right)\end{array}$} & \multirow[b]{3}{*}{$\begin{array}{c}\text { Thermal } \\
\text { energy } \\
\left(\mathrm{MWh}_{\mathrm{th}}\right)\end{array}$} \\
\hline & \multicolumn{2}{|c|}{ Electricity $\left(\mathrm{MWh}_{\mathrm{e}}\right)$} & & \\
\hline & $\begin{array}{c}\text { Resort } \\
\text { consumption }\end{array}$ & $\begin{array}{c}\text { Net } \\
\text { electricity } \\
\text { sold }\end{array}$ & & \\
\hline Annual energy demand & 2017 & - & 4483 & 605 \\
\hline $\begin{array}{l}\text { Demand satisfied by } \\
\text { solar power }\end{array}$ & 665 & 392 & 1978 & 515 \\
\hline Solar fraction & $33 \%$ & - & $44.1 \%$ & $85.1 \%$ \\
\hline
\end{tabular}


Table 2: $\quad$ Fuel consumption and avoided $\mathrm{CO}_{2}$ using CSP.

\begin{tabular}{|l|c|}
\hline Current annual diesel consumption at resort & $1,259,1281$ \\
\hline Forecasted annual consumption after integration of the CSP & 695,7361 \\
\hline Annual diesel savings & 563,3931 \\
\hline Total solar energy share & $44.7 \%$ \\
\hline Annually avoided $\mathrm{CO}_{2}$ emissions at the resort & $1500 \mathrm{t}$ \\
\hline
\end{tabular}

\subsection{Economical assessment}

From an investor's point of view, economical viability will play an important role in decision making besides the environmental benefits. Therefore, it is essential to carry out an economical assessment investigating the financial economies resulting from the lower consumption of fuel as well as the incoming revenue from selling electricity to the neighbouring island.

The assessment method adopted is the discounted cash flow method recommended by the International Energy Agency [2]. This calculation method is adapted to various renewable energy systems where the discounted cash flow, revenues and costs, are considered over the project lifetime. The year zero of the project is when the capital investment is made. The annual sum of cash flows is discounted to the year zero of the project in constant money by applying a project specific discount rate $\mathrm{k}_{\mathrm{n}}$. This discount rate depends on various factors, such as inflation rate, debt interest rate, equity interest rate and the ratio of debt equity financing. The sum of all discounted cash flows minus the investment costs is calculated and defined as the Net Present Value, NPV. The simple payback period, PB, and the profitability index, PI are also calculated. Table 3 demonstrates the financial parameters taken into consideration.

The total capital investment for the planned CSP plant is estimated at $€$ $6,656,565$. Figure 9 illustrates the cost breakdown of the different components.

Table 3: $\quad$ Financial boundary conditions of the project.

\begin{tabular}{|l|c|}
\hline Inflation rate $-\mathrm{i}$ & $2 \%$ \\
\hline real discount ratio of the project $-\mathrm{k}_{\mathrm{n}}$ & $7.8 \%$ \\
\hline project Life time $-\mathrm{n}$ & 25 years \\
\hline
\end{tabular}

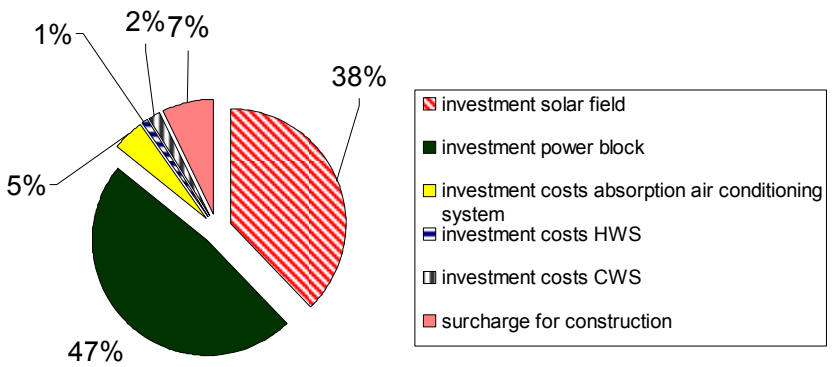

Figure 9: Capital investment breakdown. 
Table 4: $\quad$ Energy prices.

\begin{tabular}{|l|c|}
\hline $\begin{array}{l}\text { Cost of producing electricity by the diesel generators in the } \\
\text { resort }\end{array}$ & $€ 0.23 / \mathrm{kWh}$ \\
\hline Price of one litre diesel delivered to the resort & $€ 0.803 / \mathrm{kWh}$ \\
\hline Annual real increase in diesel costs & $3 \%$ \\
\hline
\end{tabular}

Table 5: Annual recurring cash flow.

\begin{tabular}{|l|c|}
\hline Operation and maintenance incl. replacement, labour and insurance & $€ 112,415$ \\
\hline Energy costs for the existing system in the resort & $€ 1,011,775$ \\
\hline Diesel cost savings after CSP & $€ 452,715$ \\
\hline Revenues due to sold electricity after CSP & $€ 88,216$ \\
\hline Total Net Recurring Costs after CSP & $€ 583,259$ \\
\hline
\end{tabular}

Tables 4 and 5 indicate the economical parameters used in calculating the annual recurring costs which are used in the financial model based on the discounted cash flow method. The model delivered the following results:

- Simple payback period, PB: 15.5 years

- Net present value, NPV: $€ 1,811,556>0$

- Profitability Index, PI: $1.2721>1$

Certified Emission Reductions, CER, credits can be obtained and sold which would additionally increase the profitability of the project. For example, if the price of selling one metric ton of $\mathrm{CO}_{2}$ is $€ 15$, additional annual revenue of $€$ 22,500 can be gained. However, since the objective of this resort is to decarbonise its operation, the carbon emissions cannot be traded and were, accordingly, not considered in this simulation.

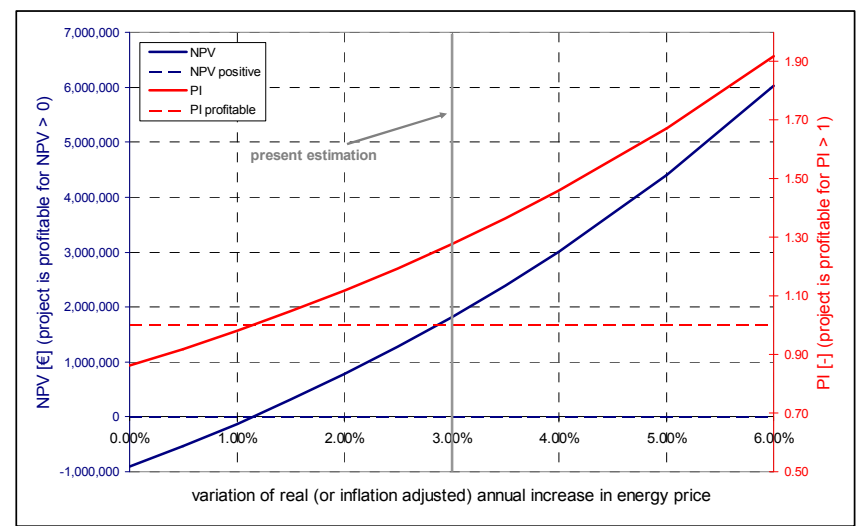

Figure 10: Variation of the diesel price increase. 
A sensitivity analysis was carried out to examine the impact of significant input parameters. The influence of annual real increase of the diesel price is illustrated in figure 10. The results show that with a real increase of $1.1 \%$ in diesel price the project begins to get profitable; with an annual increase of $6 \%$, a PI of more than 1.9 would be reached.

\section{Conclusion}

The results of this study indicate that the Maldives enjoy a good direct normal radiation which is suitable for operating CSP technology. A resort's own energy demand can be completely met during daytime using solar energy and can be extended to cover partly and/or completely the energy demand during night time by using energy storage or combining it with another renewable energy source. The economical evaluation reveals that small scale CSP installations are profitable. An additional benefit is the reduction of $\mathrm{CO}_{2}$ emissions.

The economical performance of CSP systems improves with the increase in the size of the station due to the higher specific installed capacity costs $\left(€ / \mathrm{kW}_{\mathrm{e}}\right)$ of smaller stations. The economic output is also improved with optimal use of the usable waste heat. For example, in this case, only average utilisation of the usable thermal energy ca. $63.2 \%$ was achieved. A maximum utilisation of the waste heat reaching to $90 \sim 100 \%$ would be optimal.

A funding grant or subsidized financing would also improve the economic performance of the project and encourage such types of project allowing economies of scale, lower investment costs and on the long term sustainable tourism.

\section{References}

[1] Climate-L News, http://climate-1.org/2009/03/24/undp-commends-maldives $\%$ e2\%80\%99-intention-to-become-first-carbon-neutral-country/\#more-1391

[2] International Energy Agency, Renewable Energy Technology Applications Guidelines for the Economic Analysis, IEA Publication, 1991. 